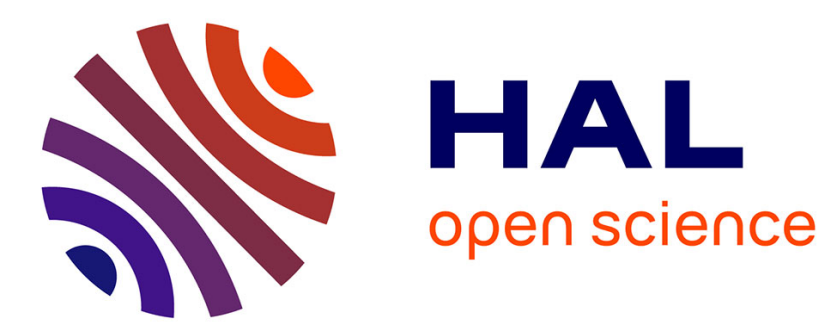

\title{
Mechanical Behaviors of $\beta$-Titanium Alloy at High Rates of Strain
}

\author{
K. Ogawa
}

\section{To cite this version:}

K. Ogawa. Mechanical Behaviors of $\beta$-Titanium Alloy at High Rates of Strain. Journal de Physique IV Proceedings, 1997, 07 (C3), pp.C3-599-C3-604. 10.1051/jp4:19973103 • jpa-00255387

\section{HAL Id: jpa-00255387 https://hal.science/jpa-00255387}

Submitted on 1 Jan 1997

HAL is a multi-disciplinary open access archive for the deposit and dissemination of scientific research documents, whether they are published or not. The documents may come from teaching and research institutions in France or abroad, or from public or private research centers.
L'archive ouverte pluridisciplinaire HAL, est destinée au dépôt et à la diffusion de documents scientifiques de niveau recherche, publiés ou non, émanant des établissements d'enseignement et de recherche français ou étrangers, des laboratoires publics ou privés. 


\title{
Mechanical Behaviors of $\beta$-Titanium Alloy at High Rates of Strain
}

\author{
K. Ogawa
}

Division of Aeronautics and Astronautics, Graduate School of Kyoto University, Yoshida Honmachi, Sakyo-ku, Kyoto 606-01, Japan

\begin{abstract}
The compressive deformation of aged and un-aged $\beta$-Titanium alloy(Ti-15V-3Cr-3Sn-3Al) was investigated at temperatures between $77 \mathrm{~K}$ and $673 \mathrm{~K}$, at strain rate up to $10^{4} \mathrm{~s}^{-1}$. Temperature and/or strain rate change tests revealed the stress-strain relations were almost independent of loading history, and consequently mechanical behaviours could be understood without considering significant change of structure evolution. Temperature rise due to the heat conversion of plastic work for both materials caused a significant work softening on the dynamic stress-strain relations at low temperatures. Thermally activated strain rate analysis(TASRA) was applied to characterize deformation mechanism by taking account of adiabatic heating and strain rate change during deformation, and the experimental results were well convinced.
\end{abstract}

\section{Introduction}

Metastable $\beta$-titanium alloy of excellent corrosion resistant and of good machinability can be aged as $(\alpha+\beta)$ two phase alloy of high-strength ratio, and will be employed as structural material for high velocity vehicles. From this point of view, it should be concerned to characterize mechanical properties of the material in wide range of temperatures and strain rates up to impact loading. There have been proposed several mechanisms such as dislocation damping to understand the high velocity deformation, but first of all , it is generally recognized that the thermally activated strain rate analysis can provide fundamental insight into the temperature and strain rate effect on the stress[1,2]. It is also essential to clarify structure evolution during deformation in a wide range of temperature and strain rate. Several authors have found that the significant rate dependence of the flow stress of soft materials such as aluminum and copper in the high strain rate ranges can be understood in connection with the strong evolution of structure during deformation. In the case of titanium alloys, on the other hand, there was not reported any appreciable temperature and strain rate history effect on the stress-strain relations, while adiabatic heating effect due to plastic work may play a predominant role on the deformation behaviour as usually expected for high strength materials[3 5]. In the present paper, the compressive deformation of aged and un-aged $\beta$-titanium alloy ,Ti-15V-3Cr-3Sn-3Al, was investigated in the wide range of temperature and strain rate, and mechanical behaviour was discussed based on the thermally activated process concept with taking account of adiabatic heating effect and strain rate change during deformation.

\section{Material and Experimental Procedures}

The material was metastable $\beta$-titanium alloy, Ti-15V-3Cr-3Sn-3Al, and was machined to un-aged compressive specimens of $3 \mathrm{~mm}$ in length and $4 \mathrm{~mm}$ in diameter, after solution treated. Chemical compositions of the material are given in Table.1. Micro-hardness measurement for isothermal aging at $723 \mathrm{~K}$ was performed as shown in Fig.1, and the aging condition for 6 hours was adapted. Static compression test at constant temperature and strain rate were carried out in the range of strain rate of $10^{-4}$ $\sim 10^{-1} \mathrm{~s}^{-1}$ and at temperatures of $77 \mathrm{~K} \sim 673 \mathrm{~K}$. Strain rate and/or temperature change tests were also conducted to evaluate the strain rate sensitivity of stress and the history effect of temperature and strain rate on the stress-strain relations. The split Hopkinson pressure bar method[6] was used for the dynamic test at strain rates of $5 \times 10^{2} \mathrm{~s}^{-1} \sim 1.2 \times 10^{4} \mathrm{~s}^{-1}$, and the apparatus and the measuring circuits are schematically illustrated in Fig.2. The striker, the input, and the output bars were of tool steel rods, and the both ends of the input and the output bars facing to the specimen were quenched and tempered to avoid possible plastic deformation. The stress waves in the input and the output bars were sensed by strain gauges cemented on the indicated positions in the figure, and were stored in the multi-channels transient recorder with sampling rate of $1 \mathrm{word} / \mu \mathrm{sec}$ after amplified up to $60 \mathrm{~dB}$ through the pre-amplifier of which distorsionless frequency response was ranged up to $2 \mathrm{MHz}$. The stress, strain, and strain rate 
Table 1 Chemical composition of the material (wt \%)

\begin{tabular}{c|c|c|c|c|c|c|c|c|c}
\hline $\mathrm{C}$ & $\mathrm{Fe}$ & $\mathrm{N}$ & $\mathrm{O}$ & $\mathrm{H}$ & $\mathrm{V}$ & $\mathrm{Cr}$ & $\mathrm{Sn}$ & $\mathrm{Al}$ & $\mathrm{TI}$ \\
\hline 0.008 & 0.178 & 0.006 & 0.122 & 0.0094 & 15.17 & 2.98 & 3.12 & 3.01 & Bal. \\
\hline
\end{tabular}

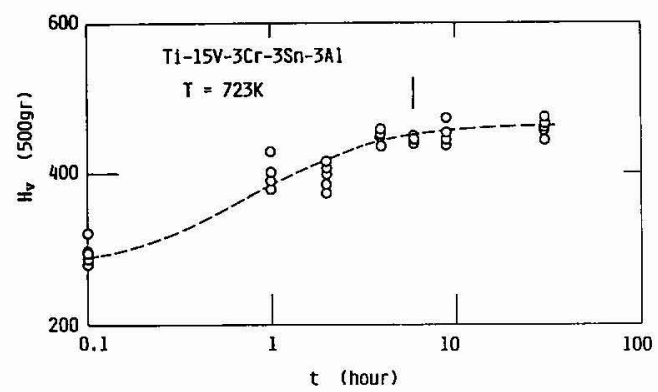

were analyzed in digital form by using the one dimensional stress wave theory as usual.

\section{Experimental Results}

The true stress-strain relations obtained by the quasistatic and the dynamic tests are represented in Figs. 3 (a)(b) for the un-aged and the aged specimens. respectively. It should be noted that the stress at $77 \mathrm{~K}$

100 and $201 \mathrm{~K}$ in dynamic test decreases with an increase of strain both for the materials. The work softening due

Fig.1 Change of Micro-hardness during isothermal aging to adiabatic heating will be discussed in details at $723 \mathrm{~K}$

afterwards. Temperature dependence of the stress at

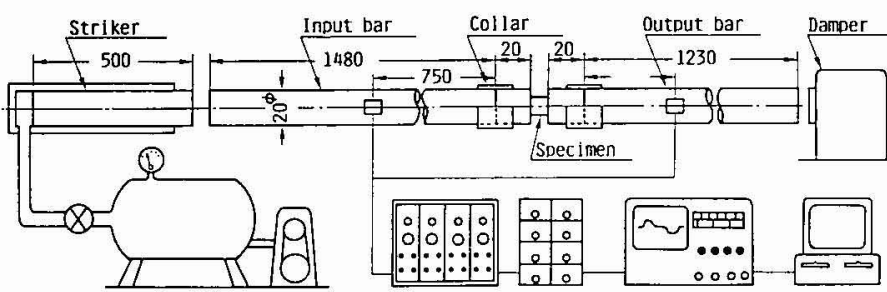
low and high strain rates is shown in Fig.4 for the respective materials together with the results for Ti-5Al$2.5 \mathrm{Sn}(\alpha)$ alloy [7]. Above room temperature, it is found that the stress only slightly decreases with temperature and almost the same kind of tendency is clearly observed both for the aged and the un-aged materials. At low temperatures, on

Fig.2 Split-Hopkinson pressure bar apparatus for dynamic compression test and measuring circuit. the other hand, the stress increases with a de-

crease of temperature, and the tendency is much more significant for the un-aged material. It is clearly observed the temperature dependency of the aged alloy is almost same as that of Ti-5Al-2.5Sn( $\alpha)$ alloy at low temperatures both for the static and dynamic deformations. These facts imply that the characteristic nature of the $\alpha$ and the $\beta$ phases respectively predominate the temperature dependence of stress at high and low temperatures even for the $(\alpha+\beta)$ two phase alloy. In Fig.5 examples of true stress-strain relation obtained by different loading paths of temperature and/or strain rate are shown. Even for the completely different loading paths, almost identical stress-strain curves were observed at the same temperature and strain rate, and consequently, it can be interpreted that the stress- strain relations are independent of the temperature and strain rate history both for the materials $[8,9]$.

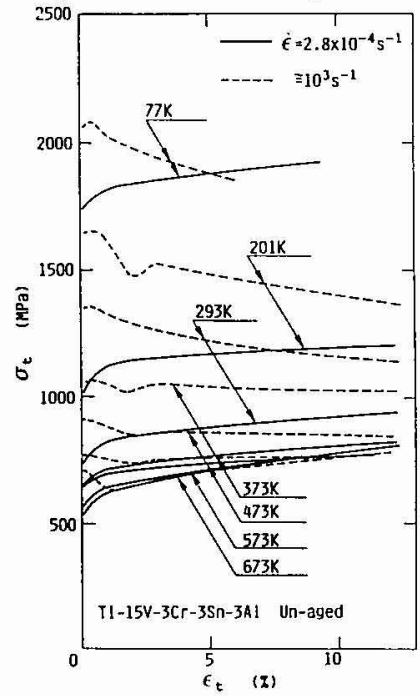

\section{Discussion}

4.1.TASRA(Thermal Activation Strain Rate Analysis)

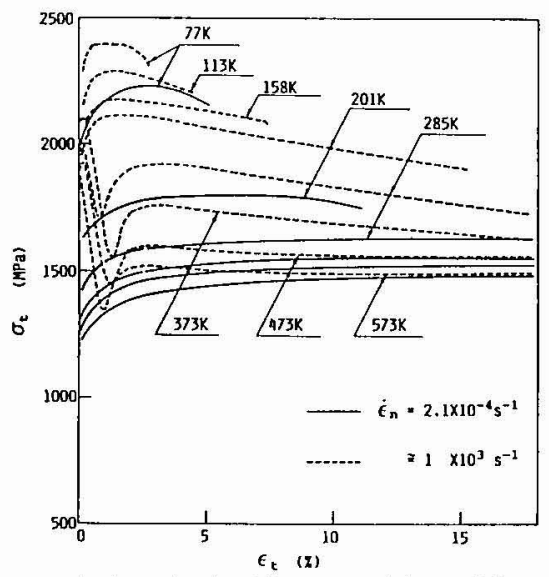

Fig.3 True stress-true strain relations obtained for un-aged (a), and for aged material (b) at quasi-static and dynamic tests

The stress, $\sigma, \quad$ can be expressed in terms of the thermal, $\sigma^{*}$, and the athermal component, $\sigma_{\mu}$, of the stress as follows.

$$
\sigma=\sigma^{*}+\sigma_{\mu}
$$

For the present materials these components can be assumed as independent of temperature and strain rate history as shown in Fig.5. The strain rate, $\dot{\varepsilon}$, of a single thermally activated flow can be expressed as

$$
\begin{aligned}
\dot{\varepsilon} & =b \rho_{\mathrm{m}} \mathrm{L} v_{0} \exp (-\mathrm{H} / \mathrm{RT}) \\
& =\dot{\varepsilon}_{0} \exp (-\mathrm{H} / \mathrm{RT})
\end{aligned}
$$

where $\boldsymbol{b}$, Burger's vector, $\rho_{\mathrm{n} 1}$. mobile dislocation density, L. average distance of short range 


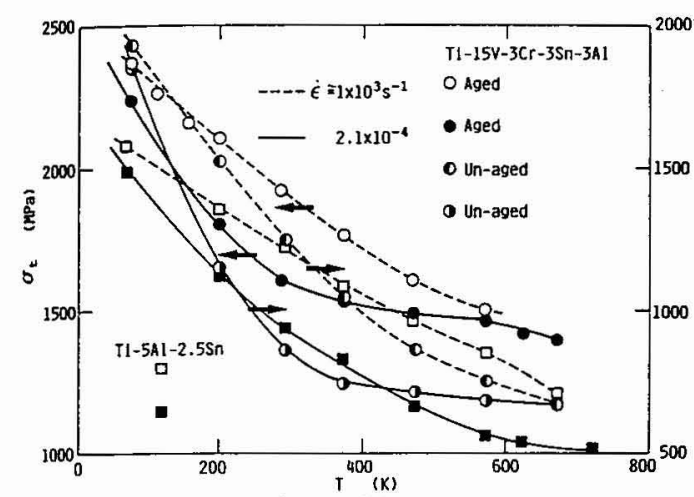

Fig.4 Temperature dependence of the stresses for un-aged and the aged materials

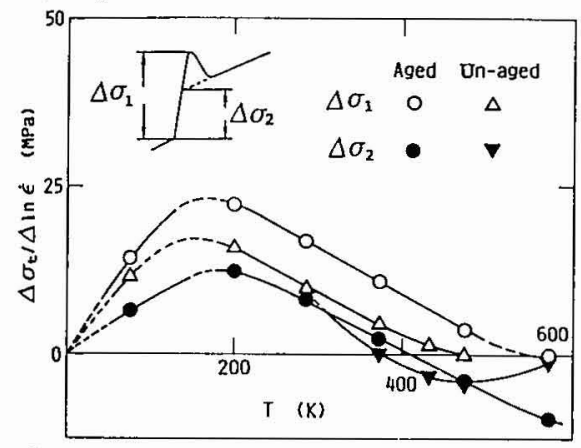

Fig.6 Strain rate sensitivity of stress evaluated by jump test at low strain rate for the un-aged and the aged materials

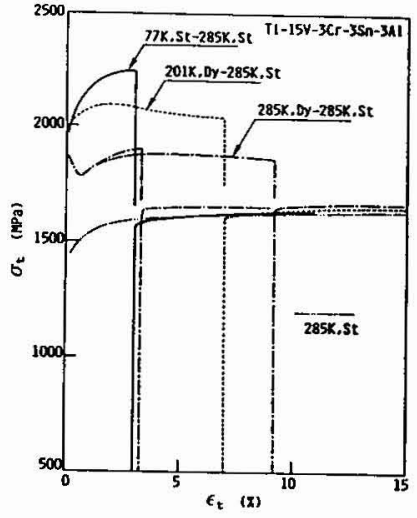

Fig.5 True stress strain relations obtained by different loading path for un-aged material

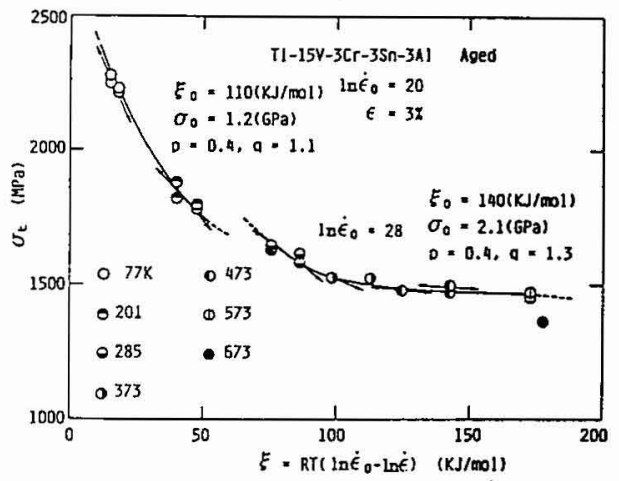

obstacles, $\nu_{0}$, part of Debye-frequency, $\mathrm{H}$, the activation energy, $R$, the gas constant and $T$ is the absolute temperature, respectively. When the activation energy is a function of $\sigma^{*}$, the stress is rewritten as;

$\sigma=\mathrm{H}^{-1}(\xi)+\sigma_{\mu}, \quad \xi=\left(\ln \dot{\varepsilon}_{0}-\ln \dot{\varepsilon}\right) \mathrm{RT}$

Strain rate sensitivity of stress at constant temperature, $\left(\Delta \sigma^{*} / \Delta \ln \dot{\varepsilon}\right)_{\mathrm{T}}$, can be evaluated by strain rate change test ( jump test ), and the following relation is maintained.

$(\Delta \sigma / \Delta \xi)=-\left(\Delta \sigma^{*} / \Delta \ln \dot{\varepsilon}\right)_{\mathrm{T}} / \mathrm{RT}$

Fig. 6 represents strain rate sensitivity of stress vs. temperature relationships together with schematic illustration of the stress response due to an abrupt change of strain rate during quasi-static deformation. For the aged material, yielding phenomena

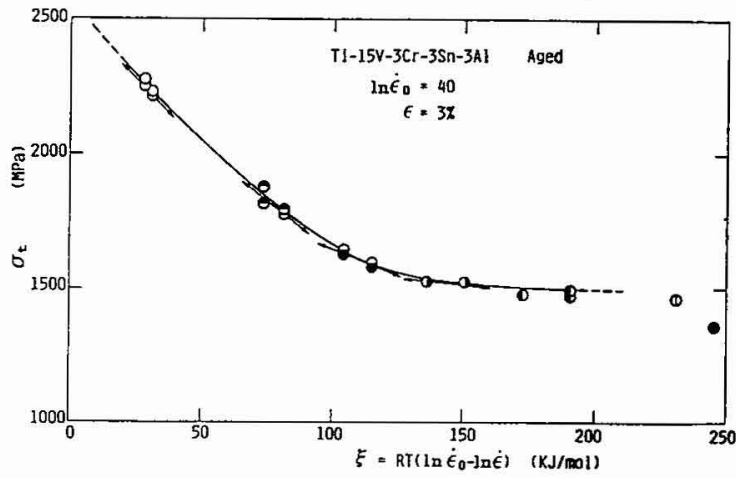

Fig.7 Relations between stress and the temperature-strain rate parameter, $\xi$, for the aged material evaluated in low strain rate range associated

with the strain rate change were observed even at low temperatures such as $77 \mathrm{~K}$, while they were only found at above room temperature in the case of the un-agedmaterial. The yielding phenomena associated with an increase of strain rate may be due to an possible increase of mobile dislocation density especially at low temperature, while at high temperatures, dynamic strain aging during deformation may contribute to the phenomena to some extent. Therefore, two kinds of strain rate sensitivity of stress can be evaluated corresponding to the $\Delta \sigma_{1}$, and the $\Delta \sigma_{2}$, indicated in the figure. It should be noted that since the stress increment , $\Delta \sigma_{1}$, was observed within a second after the strain rate was changed, mobile dislocation density might not be increased significantly in that time span, and strain rate sensitivity of stress evaluated by $\Delta \sigma_{1}$ could be used to predict deformation behaviours at high strain rate. On the other hand, strain rate sensitivity of stress evaluated by $\Delta \sigma_{2}$ would involve the stress decrement due to the increase of mobile dislocation density, and consequently may predict deformation characteristics at low 
strain rate range

In Fig. 7 all flow stress measured at are plotted versus the temperature-strain rate parameter $\xi$. Using the strain rate sensitivity of stress $\left(\Delta \sigma_{1} / \Delta l n \dot{\varepsilon}\right)_{\mathrm{T}}$ evaluated by $\Delta \sigma_{1}$ and adopting the value of $l n \varepsilon_{0}=28$, the experimental data fit a single smooth curve in the case of un-aged material as already reported[8]. In the case of the aged material, on the other hand, two curves have to be drawn as in the case of Ti$6 \mathrm{Al}-4 \mathrm{~V}(\alpha+\beta)$ alloy already reported[3]. Using the values of $\ln \dot{\varepsilon}_{0}=20$ which was also adapted for $\mathrm{Ti}-5 \mathrm{Al}-2.5 \mathrm{Sn}(\alpha)$ alloy $[2,6]$ and $\ln \varepsilon_{0}=28$, respective smooth curves fit the data at high and low temperatures as shown in (a), where the arrows indicating the gradient of the curve were directly derived from the strain rate sensitivity of the stress. When the strain rate sensitivity of stress $\left(\Delta \sigma_{2} / \Delta / n \dot{\varepsilon}\right)_{\mathrm{T}}$ was selected, a single smooth curve fits all the data by using the value of $\ln \varepsilon_{0}=40$ as shown in Fig. 7(b).

Kocks et al[10] have proposed a general form of the activation energy in terms of the thermal component of stress as follows.

$$
\left.\mathrm{H}=\mathrm{H}_{0}\left[1-(\sigma * / \sigma *)^{\mathrm{p}}\right]\right]^{\mathrm{q}}, \quad \mathrm{H}_{0}=\mathrm{R} \xi_{0}
$$

where $0<p<1,1<q<2, \sigma *_{0}$ is the value of $\sigma *$ at $0 \mathrm{~K}$, and $\xi_{0}$ is the value of $\xi$ at $\sigma *=0$. The values of $p, q, \sigma *_{0}$ and $\xi_{0}$ are given in the figures for the respective curves and are found to be independent of strain. The athermal component of stress, $\sigma_{\mu}$, can be determined as the stress at $\xi_{0}$ and is expressed as;

$$
\sigma_{\mu}=A \varepsilon^{m}
$$

where the values of $A=890 \mathrm{MPa}, m=0.09(0.02 \leq \varepsilon \leq 0.2)$, and $\ln \dot{\varepsilon}_{0}=28$ for the un-aged material, and the values of $A=1740 \mathrm{MPa}, m=0.04(\varepsilon \leq 0.04), \quad A=1580 \mathrm{MPa}, m=0.01(\varepsilon>0.04)$ at $\ln \dot{\varepsilon}_{0}=20$, and $\mathrm{A}=1750 \mathrm{MPa}, \mathrm{m}=0.05(\varepsilon \leq 0.03), A=1580 \mathrm{MPa}, \mathrm{m}=0.02(\varepsilon>0.03)$ at $\ln \dot{\varepsilon}_{0}=28$ for the aged material respectively $[8,9]$.

\subsection{Stress-Strain curve}

Since the thermal component of stress is a function of $\xi$ and the athermal component of stress depends only on the strain as was explained previously, the stress increment, $\Delta \sigma$, can be obtained as;

$$
\Delta \sigma=\Delta \sigma^{*}+\Delta \sigma_{\mu}=(\mathrm{d} \sigma * / \mathrm{d} \xi) \Delta \xi+\left(\mathrm{d} \sigma_{\mu} / \mathrm{d} \varepsilon\right) \Delta \varepsilon
$$

A temperature rise due to the adiabatic heating can be expressed as;

$\Delta \mathrm{T}=\beta \rho \gamma \sigma \Delta \varepsilon$

where $0<\beta<1.0, \rho$ is the density of material, $\gamma$ the specific heat. In the splitHopkinson pressure bar method, the strain rate , $\dot{\varepsilon}$, is evaluated in terms of the incident and the transmitted stress waves, $\sigma_{\mathrm{I}}$ and $\sigma_{\mathrm{T}}$, as; $\dot{\varepsilon}=2\left(\sigma_{\mathrm{I}}-\sigma_{\mathrm{T}}\right) /\left(\rho_{0} c_{0} l_{0}\right)$ $=2\left(\sigma_{1}-\left(A_{0} / A_{1}\right) \sigma\right) /\left(\rho_{0} c_{0} l_{0}\right)$

with assumption of identical stress state on the both sides of a specimen, where $A_{0}, A_{1}$ are the sectional areas of loading bars and a specimen, $\rho_{0}$ and $c_{0}$ are the density and the elastic wave velocity of the bars, and $l_{0}$ is the initial length of a specimen.
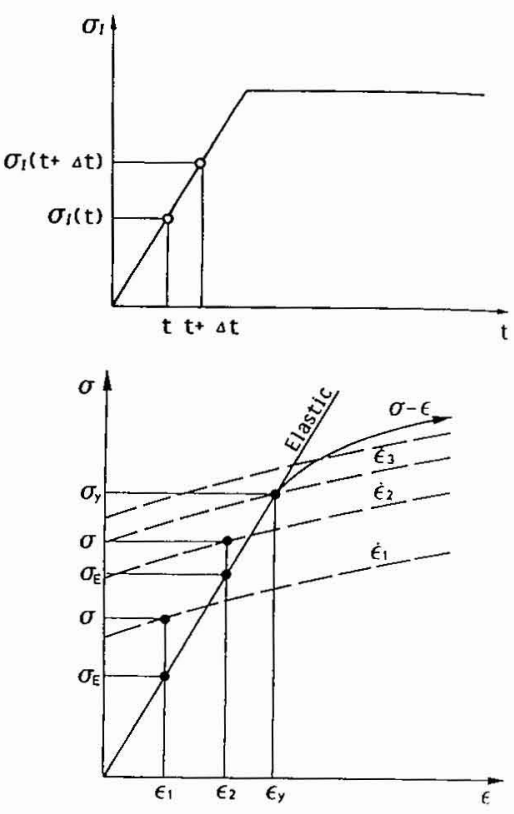

Fig.8 Calculation procedure of dynamic stress-strain relations
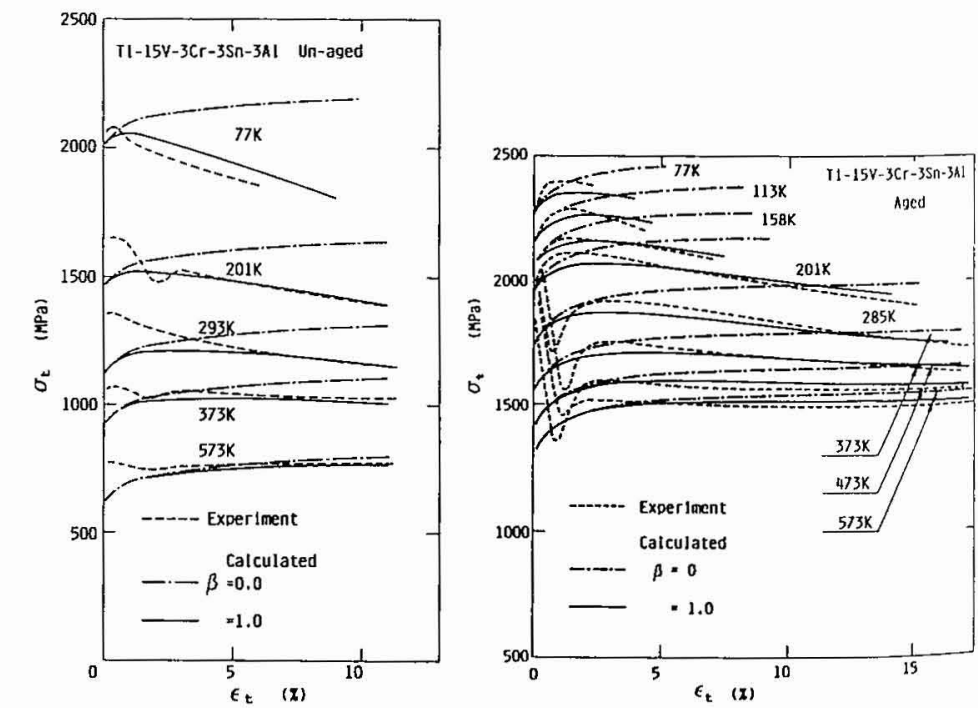

Fig.9 True stress-strain relations obtained by calculation and experiment for the un-aged (a), and the aged materials(b) 


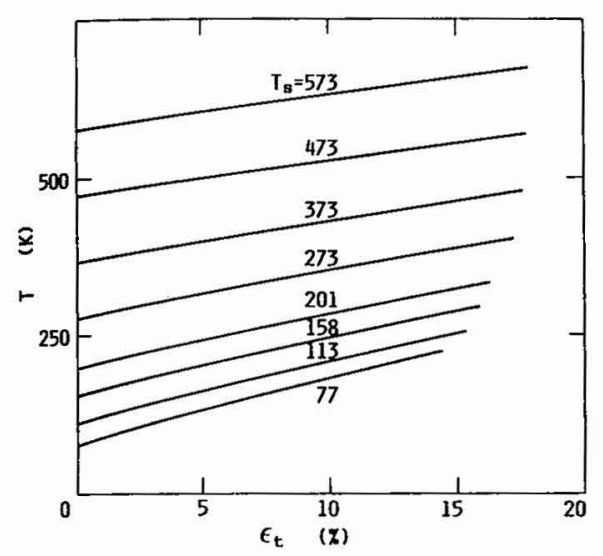

Fig.10 Calculated temperature change during high strain rate deformation for the aged material



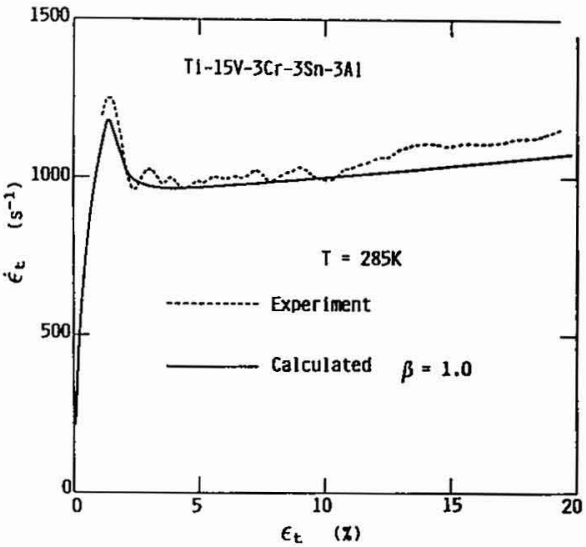

Fig. 11 Change of true strain rate during impact deformation

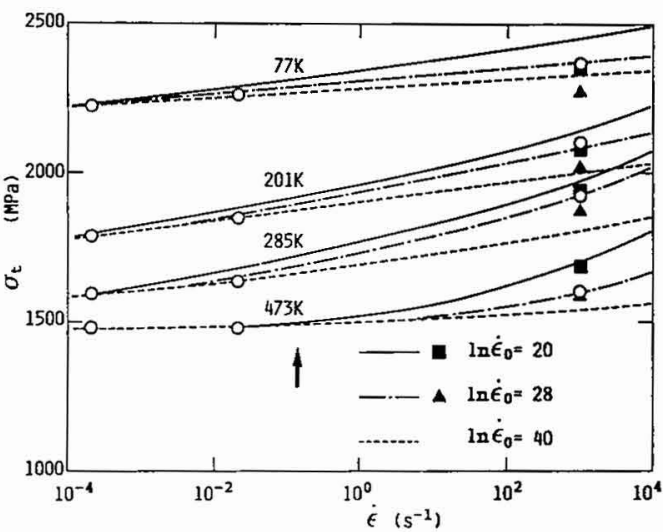

Fig.12 Relations between true stress at $10 \%$, and $3 \%$ strains and strain rate for the un-aged (a), and the aged materials(b), respectively, together with results by calculation

When the incident stress wave is given, the stress, the strain ,the strain rate , and the temperature can be evaluated by these equations from (5) to (9). Fig. 8 schematically illustrates calculation procedure of stress-strain relations. By using the stress of specimen, $\sigma(t)$ at time , $t$, and the incident stress wave $\sigma_{\mathrm{I}}(t+\Delta t)$ at time,$t+\Delta t$, to equation (9), the strain rate $\dot{\varepsilon}(t+\Delta t)$ and the strain $\varepsilon(t+\Delta t)$ can be obtained, and then the stress $\sigma(t+\Delta t)$ can be evaluated from eqs.(5) and (6). Plastic deformation will start and temperature change may occur, when the stress $\sigma(t+\Delta t)$ becomes less than the elastic stress $\sigma_{E}(t+\Delta t)=E \varepsilon(t+\Delta t)$. Thus, the same kind of procedure was repeated, and the stress-strain relations were constructed. Temperature dependency of the specific heat was assumed as $\gamma=0.00037 \mathrm{~T}+0.4(\mathrm{~J} / \mathrm{grK})[11]$, and the density of $\rho=4.76 \mathrm{gr} / \mathrm{cm}^{3}$ was used independent of temperature.

The stress-strain relations of the aged and the un-aged materials predicted for isothermal $(\beta=0.0)$ and adiabatic $(\beta=1.0)$ conditions are given in Fig. $9(\mathrm{a})(\mathrm{b})$ with the experimental results, and calculated temperature changes during high strain rate deformation are typically shown in Fig. 10 for the aged material. It can be seen that the experimental results at high strain rates are well understood by the thermally activated process concept with taking account of the adiabatic heating and the strain rate change effects during deformation. An example of strain rate during deformation obtained by the experiment and calculation is shown in Fig.11.

Fig.12(a) gives the true stress-strain rate relations for $10 \%$ strain in the case of un-aged material. The broken curves were derived by assuming isothermal deformation based on the data obtained in the quasistatic strain rate range, while the solid curves were drawn by taking account of adiabatic temperature rise and strain rate change during high strain rate deformation as explained in details. The dynamic test results especially at low temperatures could be nicely predicted by the solid curves rather than the broken curves. In the case of the aged material, the same kind of relations for $3 \%$ strain were represented in Fig.12(b) together with the calculated values. Respective curves were obtained by using the strain rate 
sensitivity of stress indicated in the figure, and the experimental results are represented by the open circles. The stresses at high strain rate denoted by the solid squares and triangles were evaluated by taking account of the adiabatic heating effect during deformation. It should be noted that for low temperatures, the experimental data at high strain rates are well consistent with the calculated results by using the strain rate sensitivity of stress without increase of mobile dislocation density as for the $\alpha$-alloy, while for high temperatures they agree with the predictions rather by using the value as for the $\beta$-alloy. The strain rate sensitivity of stress associated with an increase of mobile dislocation density well predict the experimental results at relatively low strain rate range, while a significant discrepancy is evidently expected at high strain rates where additional stress decrease will be caused by adiabatic heating effect.

\subsection{Structure evolution}

Even though it was already mentioned in Fig.5 that the stress-strain relations were almost independent of the loading history in the case of the temperature change from low to high and/or strain rate change from high to low, there were detected some history effect especially in the case of change from high to low in temperature and/or vise versa in strain rates. This fact implies that the thermal component of the stress is much more significantly influenced by the loading history effect, while the athermal component of the stress is independent of the loading history. It was already reported that mechanical twinnings were observed in the un-aged specimen dynamically deformed at low temperature, while at high temperature there could not find any mechanical twinnings even at high rates of strain such as $10^{4} \mathrm{~s}^{-1}[8]$. Since mechanical twinnings may effectively hinder the dislocation motion, structure evolution may be significant at low temperature and/or much higher strain rates, and history effect will be well understood from this point of view. Therefore, further investigation of the history effect on the thermal component of stress is needed in connection with microstructural observations to predict the stress-strain relations in the wider range of temperature and strain rates.

\section{Conclusion}

Compressive strength of aged $(\alpha+\beta)$ and un-aged ( $\beta$ )Titanium alloys(Ti-15V-3Cr-3Sn-3Al) has been investigated in the wide range of temperature from $77 \mathrm{~K}$ to $673 \mathrm{~K}$ and strain rate from $10^{-3}$ to $10^{4} \mathrm{~s}^{-1}$. Results are summarized as follows.

(1) The stress-strain relations are almost independent of temperature and strain rate history. At the strain rate of $10^{-4} \mathrm{~s}^{-1}$ the thermal component of stress is uniquely determined by the temperature-strain rate parameter $\xi$ independently of strain, and the athermal component of stress is a function of the strain only.

(2) Increasing the strain rate, a significant temperature rise is predicted due to heat conversion of plastic work during deformation, and yields a remarkable thermal softening at low temperatures.

(3) Deformation of titanium alloys investigated is well understood in connection with the thermally activated process concept and the stress-strain relations at high strain rates are satisfactorily predicted by strain rate sensitivity of stress without change of mobile dislocation density, also with taking account of adiabatic heating and strain rate change effect during deformation.

\section{References}

[1]K.Tanaka,K.Ogawa and T.Nojima,"High velocity deformation of solids", eds.J.Shioiri \& K.Kawata,pp.98107(1979),Springer-Verlag.

[2]K.Ogawa and T.Nojima, Journ. of Mater.Sci. of Jpn, 37,pp.41-47(1988)

[3]K.Ogawa,"Plasticity and Impact Mechanics ",ed.N.K.Gupta,pp. 154-172(1993),Wiley Eastern Ltd.

[4]K.Ogawa, T.Kobayashi, K. Yoshida and F.Sugiyama, Journ. of Mater.Sci. of Jpn, 43, pp. 304-309 (1994)

[5]K.Ogawa, Journ. of Mater.Sci. of Jpn,44,pp.739-744 (1995)

[6]F.E.Hauser,J.A.Simmons and J.E.Dorn,"Response of Metals to High Velocity Deformation", ed. P.G.Shewmon \& V.F.Zachay,(1961), Interscience Pub.,New York

[7]K.Ogawa, Proceedings of Dynamic plasticity and structural behaviours",eds.S.Tanimura \& A.S.Khan, pp.183-186(1995)

[8]K.Ogawa, Journ. of Mater.Sci. of Jpn, 45,pp.864-870,(1996)

[9]K. Ogawa, Journ. of Mater.Sci. of Jpn, 46, pp.118-123 (1997)

[10]U.F.Kocks,A.S.Argon and M.F.Ashby,"Thermodynamics and Kinetics of Slip",Prog.Mat.Sci, 19, (1975), Pergamon Press, Oxford.

[11]P.J.Bania, G.A.Lenning and J.A.Hall,"Beta Titanium Alloys in the 1980's",eds. R.R.Boyer \& H.W. Rosenberg, 202,(1984), Metall.Soc.AIME. 